University of Wollongong

Research Online

Faculty of Engineering - Papers (Archive)

Faculty of Engineering and Information

Sciences

$1-1-2010$

\title{
Yield curvature for seismic design of circular reinforced concrete columns
}

M Neaz Sheikh

University of Wollongong, msheikh@uow.edu.au

H. H. Tsang

University of Hong Kong

T. J. McCarthy

University of Wollongong, timmc@uow.edu.au

N.T.K Lam

University of Melbourne

Follow this and additional works at: https://ro.uow.edu.au/engpapers

Part of the Engineering Commons

https://ro.uow.edu.au/engpapers/1401

\section{Recommended Citation}

Sheikh, M Neaz; Tsang, H. H.; McCarthy, T. J.; and Lam, N.T.K: Yield curvature for seismic design of circular reinforced concrete columns 2010, 741-748.

https://ro.uow.edu.au/engpapers/1401

Research Online is the open access institutional repository for the University of Wollongong. For further information contact the UOW Library: research-pubs@uow.edu.au 


\title{
Yield curvature for seismic design of circular reinforced concrete columns
}

\author{
M. Neaz Sheikh*, H. H. Tsang †, T. J. McCarthy* and N. T. K. Lamł \\ University of Wollongong; University of Hong Kong; University of Melbourne
}

\begin{abstract}
Significant research efforts have been devoted in recent years to the development of displacement-based seismic assessment and design methodology, recognising the shortcomings of traditional, code-specified force-based procedures. Recent advances in direct displacement-based seismic design of columns rely on the estimates of yield curvature for determining seismic design forces to satisfy the specified seismic performance levels. This paper presents simple expressions for estimating the effective yield curvature for normal- and high-strength circular reinforced concrete columns based on moment-curvature analyses of a large number of column sections. Such expressions can be programmed into spreadsheet format and can be used for the direct displacement-based design of circular reinforced concrete columns. Influences of different parameters on the effective yield curvature have been quantified. Effective yield curvature is presented in terms of the gross diameter of the section and the yield strain of longitudinal reinforcement together with three modification factors that take into account the effects of the strength of concrete, axial load ratio and the amount of longitudinal reinforcement. An example illustrating the preliminary design of bridge columns based on the developed expressions is presented.
\end{abstract}

\section{Notation}

$A_{\mathrm{c}} \quad$ area of the core of columns measured out-toout of spirals

$A_{\mathrm{g}} \quad$ gross cross-sectional area

c thickness of concrete cover

D gross diameter of the cross-section

$d \quad$ effective depth, being the distance from the extreme compression fibre to the centroid of the tensile force

$f_{\mathrm{c}}^{\prime} \quad$ specified compressive strength of concrete

$f_{y} \quad$ specified yield strength of reinforcing bar

$K_{\text {eff }} \quad$ effective stiffness

$L \quad$ length of the column

$M \quad$ moment at the base of column

$M-\phi \quad$ moment-curvature

$M_{\text {eff }} \quad$ effective mass

* School of Civil, Mining and Environmental Engineering, University of Wollongong, NSW 2522, Australia.

$\dagger$ Department of Civil Engineering, University of Hong Kong, Pokfulam Road, Hong Kong.

$\ddagger$ Department of Civil and Environmental Engineering, University of Melbourne, Parkville, VIC 3010, Australia.

(MACR 900126) Paper received 17 July 2009; last revised 15 December 2009; accepted 23 December 2009.

\begin{tabular}{|c|c|}
\hline$M_{\max }$ & moment capacity of a column section \\
\hline$M_{\mathrm{yc}}$ & $\begin{array}{l}\text { moment capacity of a column section when } \\
\text { concrete strain reaches the peak stress of } \\
\text { unconfined concrete }\end{array}$ \\
\hline$M_{\mathrm{ys}}$ & $\begin{array}{l}\text { moment capacity of a column section at the } \\
\text { onset of the yielding of longitudinal } \\
\text { reinforcement }\end{array}$ \\
\hline $\operatorname{MF}\left(f_{\mathrm{c}}^{\prime}\right)$ & modification factor for concrete strength \\
\hline $\operatorname{MF}(n)$ & modification factor for axial load ratio \\
\hline $\operatorname{MF}(\rho)$ & $\begin{array}{l}\text { modification factor for longitudinal } \\
\text { reinforcement ratio }\end{array}$ \\
\hline$n$ & axial load ratio \\
\hline$P$ & axial load \\
\hline$T_{\text {eff }}$ & effective period \\
\hline$V$ & base shear force \\
\hline$\Delta_{\mathrm{u}}$ & maximum allowable displacement \\
\hline$\Delta_{\mathrm{y}}$ & effective yield displacement \\
\hline$\varepsilon_{\mathrm{ys}}$ & yield strain of longitudinal reinforcement \\
\hline$\xi$ & damping ratio \\
\hline$\rho$ & $\begin{array}{l}\text { longitudinal reinforcement ratio (ratio of } \\
\text { area of longitudinal reinforcement to gross } \\
\text { cross-sectional area) }\end{array}$ \\
\hline$\phi_{\mathrm{y}}$ & effective yield curvature \\
\hline$\phi_{\mathrm{yc}}$ & $\begin{array}{l}\text { curvature when the peak stress of the } \\
\text { unconfined concrete is reached }\end{array}$ \\
\hline$\phi_{\mathrm{ys}}$ & $\begin{array}{l}\text { curvature at the onset of yielding of the } \\
\text { logitudinal reinforcement }\end{array}$ \\
\hline
\end{tabular}




\section{Introduction}

Earthquake engineering research over the past three decades resulted in force-based (FB) structural assessment, design and detailing procedures, incorporating capacity principles and ensuring adequate safety of the structure without significant damage and collapse when subject to severe ground shaking (Park and Paulay, 1975; Park, 1997; Paulay and Priestley, 1992). Certain fundamental assumptions in the FB design procedures have, however, been found to be not representative of actual structural behaviour. The stiffness of the structure, which is used for determining the natural period of the structure and hence the amount of equivalent lateral forces induced by earthquake action, is not known initially. Different codes take different approaches in estimating their stiffnesses. Moreover, the effective stiffness of a cracked reinforced concrete (RC) member is not constant but increases with increasing flexural strength (Priestley et al., 2007). Difficulties in determining the structural stiffness of RC members result in significant inaccuracies in estimating the natural period of the structure. These errors are then translated into errors in estimating strength demand and distribution of forces calculated from FB design procedures.

Considering the inherent limitations of FB procedures, displacement-based (DB) procedures have been proposed in recent years where displacement demand is compared with the displacement capacity of the structure. Such procedures are transparent as they consider the true behaviour of the structure and will likely be incorporated in future seismic design codes. In DB procedures, the design force levels are determined based on the estimate of yield displacement of the structure. The ultimate displacement demand is first compared with the yield displacement for estimating the ductility demand of a cross-section. The section ductility demand can be used for calculating the effective damping level which is then used for calculating the inelastic displacement demand and the effective natural period based on the elastic displacement response spectrum (Miranda and Garcia, 2002). The comparison between yield displacement and ultimate displacement is also important for evaluating the seismic performance of a structure or structural element under a given level of earthquake shaking.

The intended failure mechanism for the majority of bridge piers and columns involves the formation of plastic hinges at critical locations (i.e. plastic hinge regions). The yield displacement of RC columns can be estimated using simple expressions that account for the flexural deformation of the column (Priestley et al., 2007). Such expressions can be developed based on the yield curvature of the column at the critical location. Previous studies (Montes and Aschleim, 2003; Priestley et al. 1996, 2007) indicate that yield curvature is not sensitive to the quantity of longitudinal reinforcement used in the member. This allows simple expressions to be used for estimating the curvature of the member at yield. Once the yield curvature and the yield strength are known, the cracked stiffness of the member can also be readily obtained.

This paper aims at developing simple expressions for estimating yield curvature of normal- and high-strength circular RC columns based on moment-curvature analysis of a large number of column sections.

\section{Previous studies on yield curvature}

Priestley et al. $(1996,2007)$ proposed a formula for calculating the yield displacement of circular bridge columns taking into account shear contribution and strain penetration of the longitudinal reinforcement into the foundation. Yield curvature $\left(\phi_{\mathrm{y}}\right)$ has been expressed in terms of the yield strain of the longitudinal reinforcement $\left(\varepsilon_{\mathrm{ys}}\right)$ and the diameter of the gross section $(D)$ of the piers (Equation 1). As mentioned earlier, the effective yield curvature of a cross-section does not depend significantly on the ratio of the longitudinal reinforcement $(\rho)$, whereas effective stiffness is almost proportional to the ratio of the longitudinal reinforcement (given that stiffness is strength divided by displacement at yield). Hence, the effective yield curvature should be considered as one of the basic properties of a cross-section. In Priestley's formula (Equation 1) no indication has been given regarding the sensitivity of the yield curvature to the ratio of the longitudinal reinforcement. Moreover, the axial load ratio, $n=P / f_{\mathrm{c}}^{\prime} A_{\mathrm{g}}$ (where $P$ is the axial load, $f_{\mathrm{c}}^{\prime}$ is the concrete compressive strength and $A_{\mathrm{g}}$ is the gross area of the cross-section) which may affect the yield curvature, has not been parameterised and no limitation has been suggested for the application of the formula. However, bridge columns designed according to most design codes may have the axial load ratio $(n)$ of around $10 \%$.

$$
\phi_{\mathrm{y}}=2.25 \times \frac{\varepsilon_{\mathrm{ys}}}{D}
$$

Montes and Aschleim (2003) proposed simple expressions for calculating the effective yield curvature for different yield strengths $\left(f_{\mathrm{y}}\right)$ of steel reinforcement based on moment-curvature $(M-\phi)$ analyses. Effective yield curvature has been expressed in terms of the yield strain of longitudinal reinforcement $\left(\varepsilon_{\mathrm{ys}}\right)$ and the effective depth of the section, $d$ (depth of the extreme tension reinforcement) as shown in Equations $2 \mathrm{a}$ and $2 b$. Less scatter was observed in the estimate of the effective yield curvature when parameterised in terms of effective depth of the section, $d$.

$$
\begin{aligned}
& \phi_{\mathrm{y}}=2.4 \times \frac{\varepsilon_{\mathrm{ys}}}{d} \text { for } f_{\mathrm{y}}=400 \mathrm{MPa} \\
& \phi_{\mathrm{y}}=2.3 \times \frac{\varepsilon_{\mathrm{ys}}}{d} \text { for } f_{\mathrm{y}}=500 \mathrm{MPa}
\end{aligned}
$$

Magazine of Concrete Research, 2010, 62, No. 10 
One of the most important observations from the study is the sensitivity of the yield curvature to the level of axial load ratio, $P / f_{\mathrm{c}}^{\prime} A_{\mathrm{g}}$, as seen in Equations $3 \mathrm{a}$ and $3 b$

$$
\begin{gathered}
\phi_{\mathrm{y}}=\frac{\varepsilon_{\mathrm{ys}}}{d}\left[2 \cdot 5-\left(a-b \frac{P}{f_{\mathrm{c}}^{\prime} A_{\mathrm{g}}}\right)^{2}\right] \\
\text { for } f_{\mathrm{y}}=400 \mathrm{MPa} \\
\phi_{\mathrm{y}}=\frac{\varepsilon_{\mathrm{ys}}}{d}\left[2 \cdot 4-\left(a-b \frac{P}{f_{\mathrm{c}}^{\prime} A_{\mathrm{g}}}\right)^{2}\right] \\
\text { for } f_{\mathrm{y}}=500 \mathrm{MPa}
\end{gathered}
$$

Values of $a$ and $b$ have been found from parabolic curve fitting and are expressed as functions of the effective depth for three cross-sections. For other crosssections, it is recommended to obtain the values of $a$ and $b$ by linear interpolation.

The above studies have not given any indication on the sensitivity of the effective yield curvature to the quantity of longitudinal reinforcement $(\rho)$. Also, highstrength concrete was not within the scope of the studies and, indeed, concrete strength has not been explicitly parameterised in the recommended expressions. It is noted that high-strength concrete with compressive strength of up to $100 \mathrm{MPa}$ is now being increasingly used in the construction of bridge columns and is also permitted by most design codes. Another omission is that the thickness of the concrete cover $(c)$ has also not been parameterised in the recommended expressions. The effect of concrete cover is important to determine whether the gross diameter of the section $(D)$ or the effective diameter $(d)$ should be used for the expression of yield curvature.

\section{Modelling of columns}

\section{Analytical modelling of RC columns}

Reinforced concrete is a highly non-linear material. Realistic constitutive law of RC elements is complex as the non-linearity arising from concrete and reinforcement needs to be appropriately incorporated to simulate the experimentally observed behaviour of RC elements accurately.

\section{Stress-strain relationship of concrete}

The uniaxial confined concrete model of Légeron and Paultre (2003), which is based on strain compatibility and transverse force equilibrium, has been chosen as the constitutive law of concrete for the analytical modelling of RC columns. The model has been validated with test results from more than 200 circular and square large-scale columns tested under slow and fast concentric loading. In the model, the behaviour of confined concrete is related to the effective confinement index, which takes into account the amount of trans- verse confinement reinforcement, the spatial distribution of the transverse and longitudinal reinforcement, the concrete strength and the transverse reinforcement yield strength.

\section{Stress-strain relationship of longitudinal bars}

An accurate model of a stress-strain relationship of steel bars needs to simulate: $(a)$ elastic, yielding and strain hardening behaviour; $(b)$ compression behaviour including buckling of bars; and (c) low cycle fatigue and premature rupture of bars in tension.

The Gomes and Appleton (1997) model has been chosen as the constitutive law of reinforcing bars, since it is simple and predicts the above characteristics of reinforcing bars well. The model takes into account the effect of inelastic buckling of longitudinal reinforcing bars in a simplified way based on the plastic mechanism of a buckled bar.

\section{Modelling sectional behaviour}

In this study, the complete moment-curvature responses of column sections were computed using the computer program MNPHI (Paultre, 2001), which incorporates the constitutive laws of concrete and that of the reinforcing bars. The program uses a layered representation of the section where each layer is separated into a confined core layer and an unconfined cover layer with the corresponding material properties. It calculates the moment-curvature response by an incremental analysis assuming a plane section remaining plane (before and after bending). The program also takes into account the spalling of concrete cover.

\section{Comparison with experimental results}

To evaluate the capability of the developed analytical model, experimental results of a large number of columns tested under cyclic loading have been compared. The test variables include main parameters of interest, such as column cross-sectional dimension, yield strength of concrete and steel reinforcement, axial load ratio, longitudinal reinforcement ratio and concrete cover. Owing to space restrictions in this paper, moment-curvature predictions of bridge columns 407, 415 and 430 (reported by Lehman et al., 2004) are presented in Figure 1. The diameter of the columns is $610 \mathrm{~mm}$ with longitudinal reinforcement ratios of $0.75 \%, 1.5 \%$ and $3 \%$ respectively. The axial load ratio of the columns is $0 \cdot 07$. Excellent agreement has been observed between the experimental results and analytical predictions from this study. The developed analytical model has been used for the development of moment-curvature relationships in this study.

\section{Definition of yield curvature}

Different definitions of yield curvature have been found in the literature based on both experimental and analytical results. For seismic design of RC columns, effective yield curvature rather than true yield curvature 


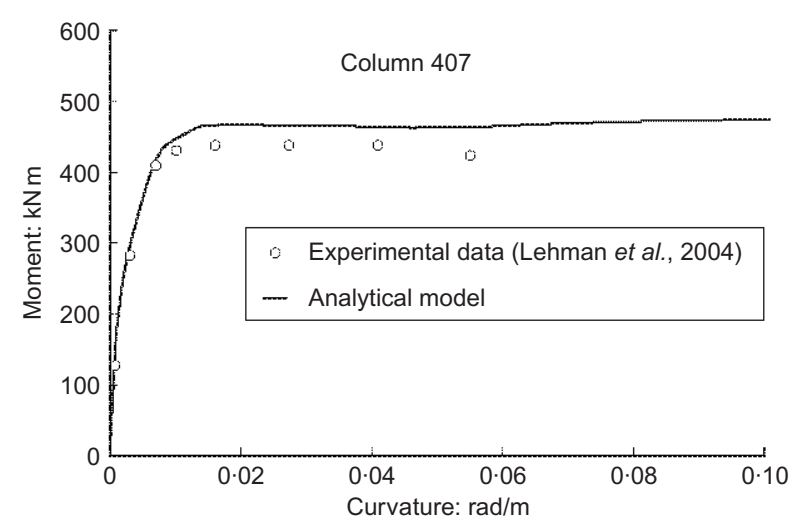

(a)

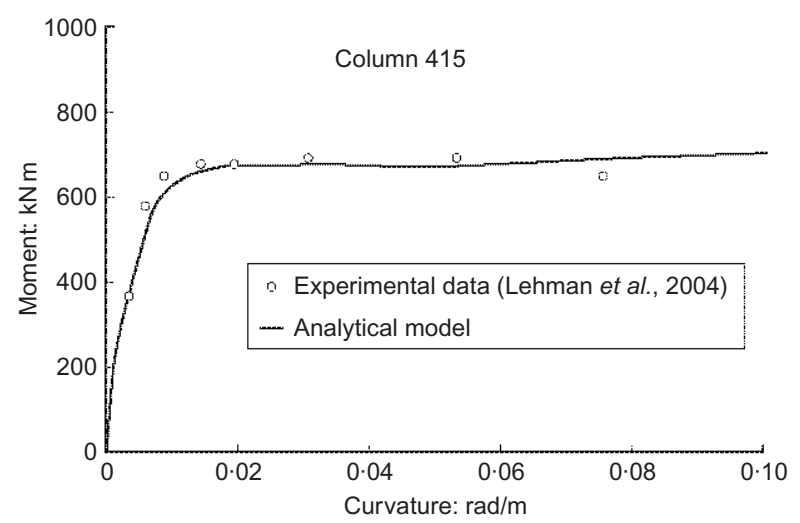

(b)

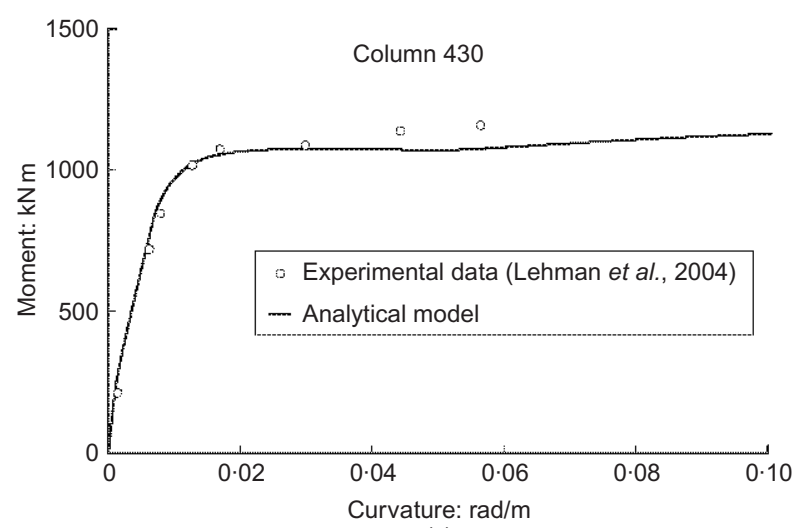

(c)

Figure 1. Experimental results compared with analytical predictions

is of interest. Priestley et al. (1996) defined the effective yield curvature as the intersection of the line through the first yield point with the line drawn tangentially to the moment-curvature $(M-\phi)$ diagram. This definition of effective yield curvature can be useful in the presentation of the experimental results (when sufficient data are not available for reliably estimating the flexural strength of concrete). However, there is an element of user subjectivity in fitting the tangent line as different tangent lines can be fitted to the softened branch of moment-curvature curve. The definition adopted in this paper is based on the first yield point (either concrete or steel) and the maximum flexural strength of the column (Equation 4)

$$
\phi_{\mathrm{y}}=\operatorname{MIN}\left(\phi_{\mathrm{yc}} \frac{M_{\mathrm{max}}}{M_{\mathrm{yc}}} ; \phi_{\mathrm{ys}} \frac{M_{\mathrm{max}}}{M_{\mathrm{ys}}}\right)
$$

where $\phi_{\mathrm{yc}}$ is the curvature when the peak stress of the unconfined concrete is reached and $M_{\mathrm{yc}}$ is the moment corresponding to $\phi_{\mathrm{yc}} ; \phi_{\mathrm{ys}}$ is the curvature at the onset of yielding of the longitudinal reinforcement and $M_{\mathrm{ys}}$ is moment corresponding to $\phi_{\mathrm{ys}}$; and $M_{\max }$ is the moment capacity of the section. The definition of yield curvature adopted here (Figure 2) avoids user subjectivity as it is based on the maximum flexural strength of the column. This allows engineers to develop bi-linear moment-curvature response functions which are of practical importance to the structural design of $\mathrm{RC}$ columns.

\section{Estimation of yield curvature}

Expressions for the effective yield curvature presented in this paper are based on the moment-curvature response of columns according to the methodology developed in the previous section It was observed that the effective yield curvature of the columns is influenced by the overall size of the cross-section gross diameter, $D$, the axial load ratio, $n$, the strength of concrete, $f_{\mathrm{c}}^{\prime}$, and yield strength of longitudinal reinforcement, $f_{\mathrm{y}}$, and to some extent on the ratio of longitudinal reinforcement, $\rho$, and the depth of concrete cover, $c$ (or equivalently the ratio of area of the gross section to the area of the core, $\left.A_{\mathrm{g}} / A_{\mathrm{c}}\right)$.

Circular column sections of diameters from $0.5-$ $2.5 \mathrm{~m}$ having axial load ratios, $n$, of $0-0.5$ and reinforcement ratios, $\rho$, of $1-6 \%$ of the gross cross-sectional area have been considered. Both normal- and high-strength columns were within the scope of the study. Concrete strengths, $f_{\mathrm{c}}^{\prime}$, ranged from $30 \mathrm{MPa}$ to $100 \mathrm{MPa}$, which cover the wide range of concrete strength currently used for the design of concrete columns and also the maximum limit permitted by most design codes. Concrete

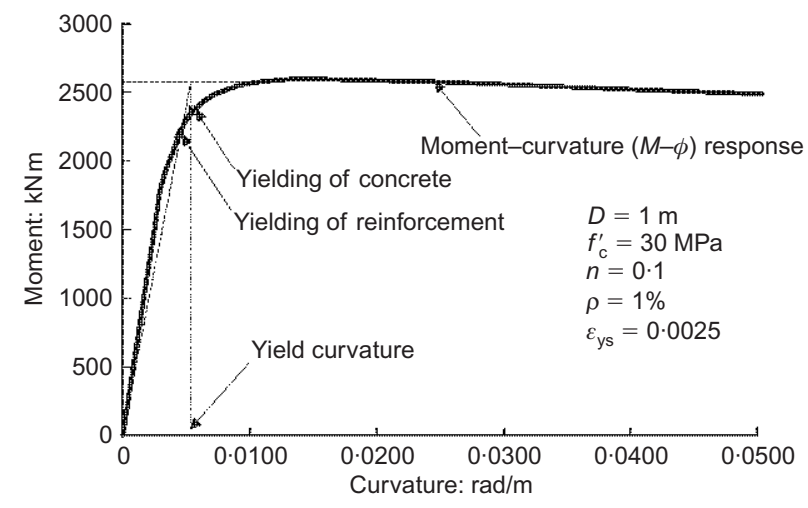

Figure 2. Moment-curvature $(M-\phi)$ relationship of $R C$ column

Magazine of Concrete Research, 2010, 62, No. 10 
cover, $c$, has been considered to be $0.05 \mathrm{~m}$. However, to study the influence of the concrete cover on the effective yield curvature of columns, cross-sections with concrete covers varying between 0.03 and $0.1 \mathrm{~m}$ were analysed. The yield strength, $f_{\mathrm{y}}$, of reinforcing bars was assumed to be $400 \mathrm{MPa}, 500 \mathrm{MPa}$ and $600 \mathrm{MPa}$. The modulus of elasticity of the reinforcing bar was taken as $200 \mathrm{GPa}$.

\section{Influence of section dimension}

Previous research on yield curvature proposed expressions for yield curvature in terms of overall crosssection dimension (Priestley et al., 1996, 2007) or the effective depth of the cross-section (Montes and Aschleim, 2003). In the current paper, the effective yield curvature is presented in terms of the overall cross-section dimension, $D$.

It is evident from Figure 3 that the effective yield curvature is significantly dependent on $D$ and that the best-fit curve can be obtained when it is expressed in terms of $D^{-1 \cdot 1}$. The following expression is proposed for estimating the effective yield curvature of normal strength $\left(f_{\mathrm{c}}^{\prime}=30 \mathrm{MPa}\right)$ concrete columns while ignoring the effects of axial load $(n=0)$

$$
\phi_{\mathrm{y}}=2 \cdot 0 \times \frac{\varepsilon_{\mathrm{ys}}}{D^{1 \cdot 1}}
$$

It is seen from Figure 3 that previous studies have overestimated the effective yield curvature, especially when $D$ is small. This overestimation is also apparent from results presented in Montes and Aschleim (2003).

Intuitively, the ratio of the area of the gross section to the area of the core $\left(A_{\mathrm{g}} / A_{\mathrm{c}}\right.$ or the thickness of concrete cover) may have some influence on the estimates of effective yield curvature. Figure 4 presents the influence of concrete cover on the estimation of effective yield curvature. All data points have been normalised with respect to the yield curvature when the concrete cover is $0.05 \mathrm{~m}$.

It is evident from Figure 4 that concrete cover (or $\left.A_{\mathrm{g}} / A_{\mathrm{c}}\right)$ does not have a significant influence on the effective yield curvature. The influence is even less when $D$ is greater than $1 \mathrm{~m}$. However, the concrete cover, $c$, may have some effects, although not signifi-

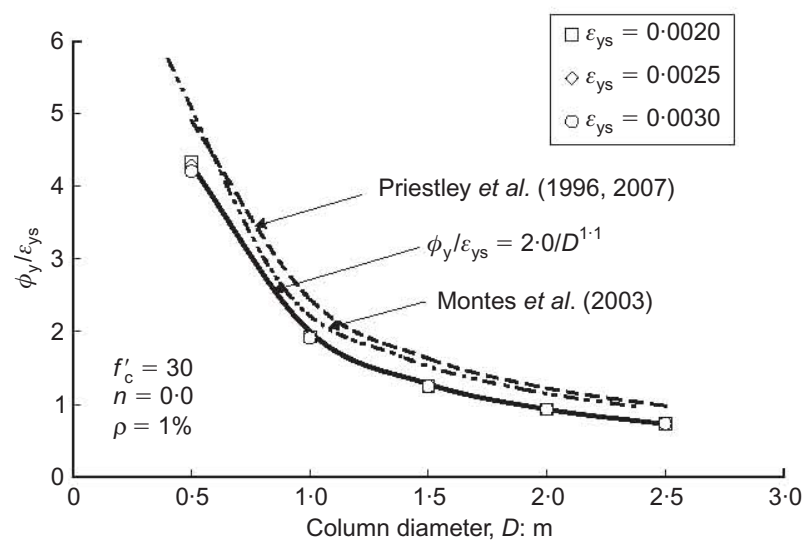

Figure 3. Influence of column diameter

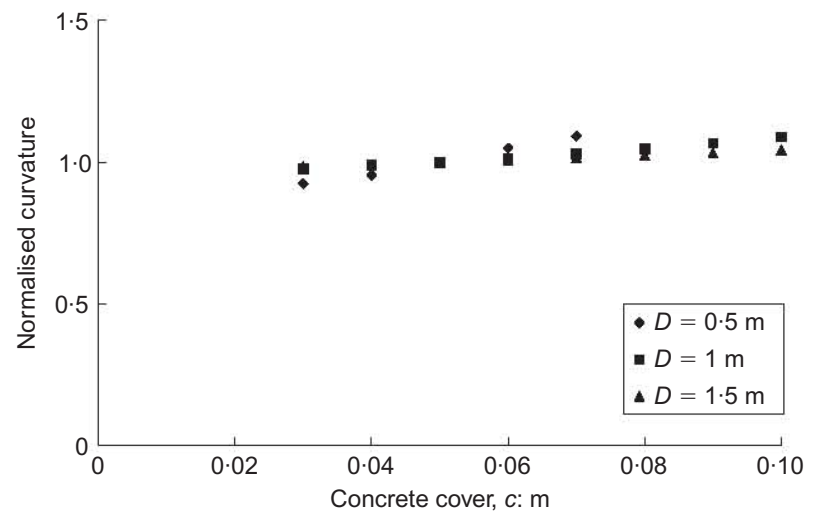

Figure 4. Influence of concrete cover

cant, when $D$ is less than $0.5 \mathrm{~m}$. It is noted that concrete cover of up to $0.07 \mathrm{~m}$ has been considered for a $0.5 \mathrm{~m}$ diameter column (Figure 4). It is apparent that the gross diameter of the cross-section is a better parameter to use than the effective depth of the section.

\section{Influence of the strength of concrete}

Figure 5 shows the influence of the concrete strength, $f_{\mathrm{c}}^{\prime}$, on the effective yield curvature. The yield curvature, normalised with respect to the effective yield curvature of $30 \mathrm{MPa}$ concrete, varies from 1.0 to 0.9 when the concrete strength varies from $30 \mathrm{MPa}$ to $100 \mathrm{MPa}$. Thus, ignoring the effects of concrete strength could result in overestimation of the effective yield curvature by up to $10 \%$ (when the concrete strength is $100 \mathrm{MPa}$ ). However, when subjected to varying axial load ratio, the strength of concrete significantly influences the effective yield curvature (see next subsection). A modification factor has been proposed to take into account the effects of the strength of concrete (Equation 6).

$$
\operatorname{MF}\left(f_{\mathrm{c}}^{\prime}\right)=1.25 f_{\mathrm{c}}^{\prime-0.07}
$$

\section{Influence of axial load}

Figure 6 shows the influence of axial load ratio on the normalised yield curvature (normalised with respect

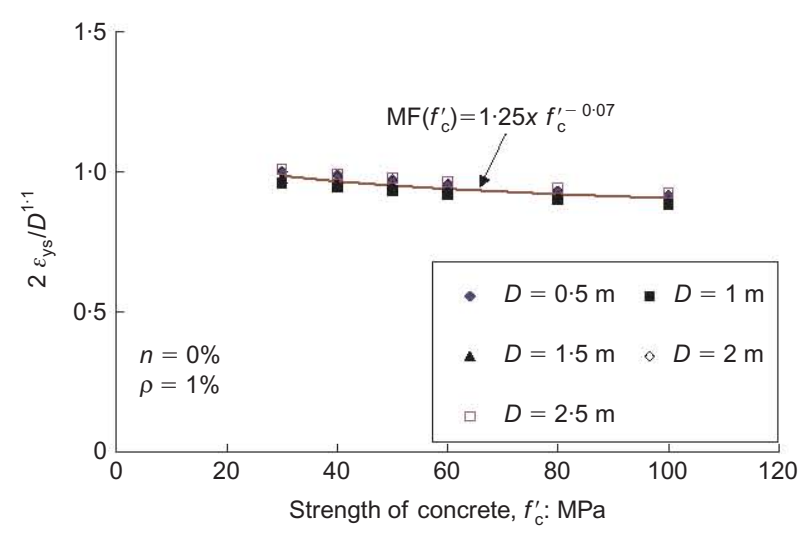

Figure 5. Influence of strength of concrete 


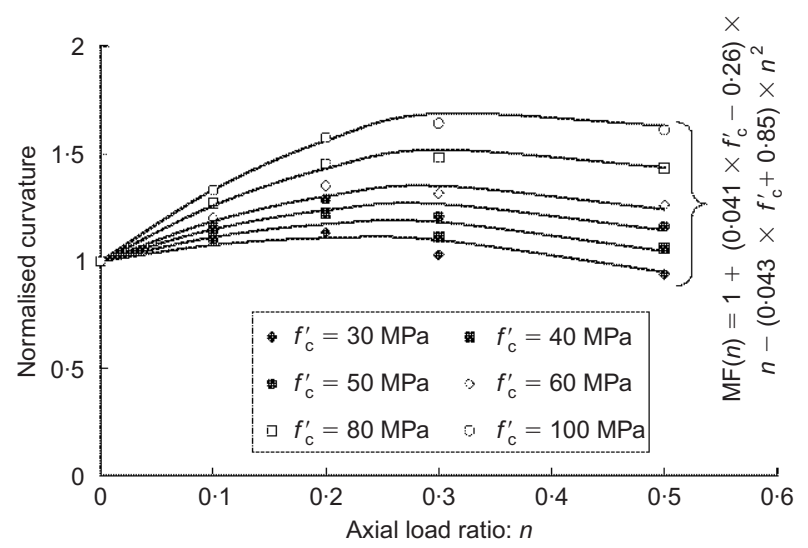

Figure 6. Influence of axial load

to the yield curvature at zero axial load level). The data points shown in Figure 6 represent the average values of the normalised yield curvature for all the section dimensions considered $(0.5-2.5 \mathrm{~m})$. It is seen that concrete strength influences the yield curvature when subject to varying axial load ratio. Yield curvature is shown to increase with increasing axial load ratios from 0 to 0.3 and beyond that point effective yield curvature decreases with increasing axial load ratio. Similar observations can be found in Montes and Aschleim (2003). A modification factor has been proposed to take into account these observations (Equation 7).

$$
\begin{aligned}
\operatorname{MF}(n)=1 & +\left(0.041 \times f_{\mathrm{c}}^{\prime}-0.26\right) \\
& \times n-\left(0.043+f_{\mathrm{c}}^{\prime} 0.85\right) \times n^{2}
\end{aligned}
$$

where $n$ is the axial load ratio and $f_{\mathrm{c}}^{\prime}$ is the strength of concrete. It is important to mention that such modification factors may overestimate the yield curvature for smaller diameter section $(D<0.5 \mathrm{~m})$ under high axial load. However, bridge piers are normally subjected to low levels of axial load (around 10\%) and usually have larger cross-sections.

\section{Influence of longitudinal reinforcement ratio}

As mentioned in the section 'Previous studies on yield curvature', the effects of longitudinal reinforcement ratio, $\rho$, on the effective yield curvature, have not yet been explicitly examined. It has been argued that the longitudinal reinforcement ratio does not significantly influence the effective yield curvature. Figure 7 presents the influence of the longitudinal reinforcement ratio on the normalised effective yield curvature (normalised with respect to the effective yield curvature when longitudinal reinforcement ratio $=1 \%$ ). It has been observed that effective yield curvature increases with the increase of the longitudinal reinforcement ratio. However, the rate of increase is insignificant when the longitudinal reinforcement ratio is more than $3 \%$. In most bridge design codes, the permitted amount of longitudinal reinforcement varies from 0.8 to $6 \%$, although in real practice a longitudinal reinforcement

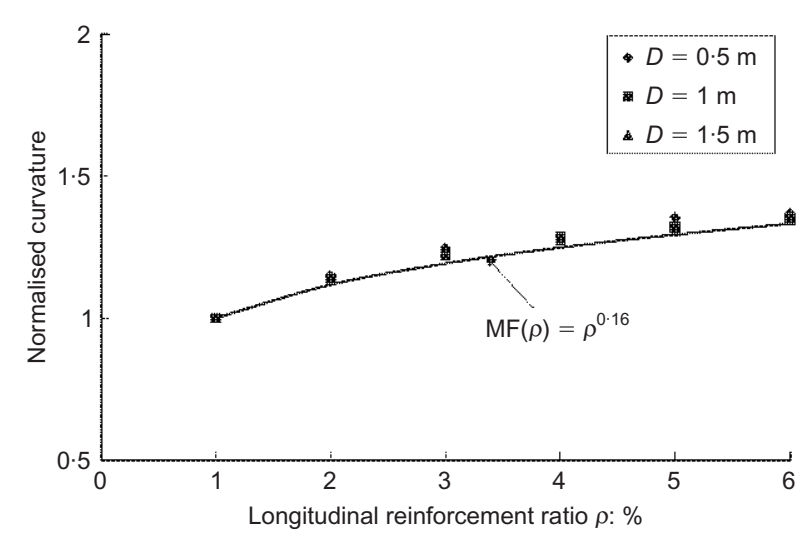

Figure 7. Influence of longitudinal reinforcement ratio

ratio less than $3 \%$ is usually provided to avoid congestion of reinforcement.

Results shown in Figure 7 are based on the condition of no axial load and the difference would be even lower if the axial load level were considered (i.e. $n>0$ ). A modification factor has been proposed to take into account effects of longitudinal reinforcement ratio (Equation 8)

$$
\operatorname{MF}(\rho)=\rho^{0 \cdot 16}
$$

\section{Estimation of effective yield curvature}

Based on the parametric studies conducted on more than 200 columns, algebraic expressions have been developed (Equation 9) for estimating effective yield curvature. It was found that ignoring the effects of the longitudinal reinforcement ratio would only marginally underestimate the effective yield curvature and hence its effects could be neglected in the preliminary design of the RC column. However, parameterising the effects of the longitudinal reinforcement ratio can be useful for accurate evaluation of existing concrete columns.

$$
\begin{gathered}
\phi_{\mathrm{y}}=2.0 \times \frac{\varepsilon_{\mathrm{ys}}}{D^{1 \cdot 1}} \times \operatorname{MF}\left(f_{\mathrm{c}}^{\prime}\right) \times \operatorname{MF}(n) \times \operatorname{MF}(\rho) \\
\operatorname{MF}\left(f_{\mathrm{c}}^{\prime}\right)=1.25 \times f_{\mathrm{c}}^{\prime-0.07} \\
\operatorname{MF}(n)=1+\left(0.041 \times f_{\mathrm{c}}^{\prime}-0.26\right) \\
\times n-\left(0.043 \times f_{\mathrm{c}}^{\prime}+0.85\right) \times n^{2} \\
\operatorname{MF}(\rho)=\rho^{0.16}
\end{gathered}
$$

The above equations can be easily programmed into an Excel spreadsheet for estimating effective yield curvature for a wide range of concrete columns having different axial load ratios, concrete strengths and longitudinal reinforcement ratios.

Figure 8 indicates that the predicted values of effective yield curvatures are within $10 \%$ of the calculated effective yield curvatures. Several data points are significantly deviated from the calculated values. These data points are for $0.5 \mathrm{~m}$ diameter columns with axial load ratios between $0 \cdot 3$ and $0 \cdot 5$. It was mentioned earlier that $\operatorname{MF}(n)$ may overestimate the effective yield

Magazine of Concrete Research, 2010, 62, No. 10 


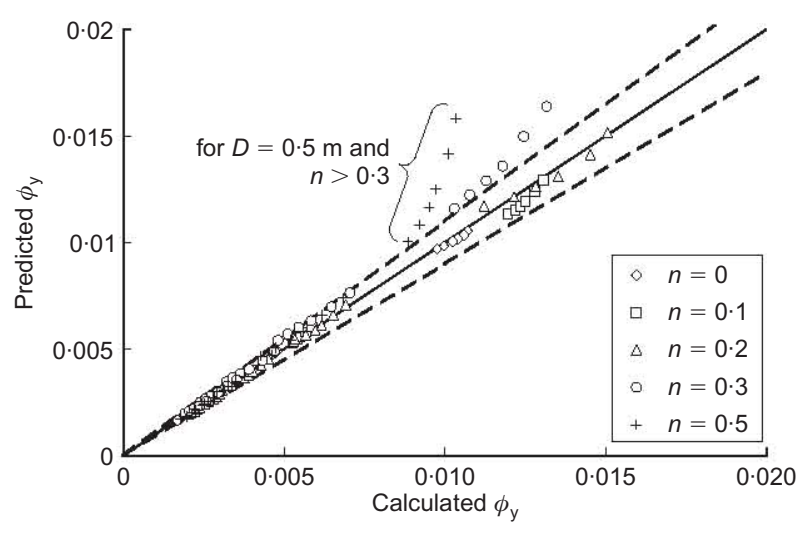

Figure 8. Calculated against predicted effective yield curvature

curvature for small-diameter columns under higher axial load ratio. However, such cases are not common in bridge construction.

\section{Design of a bridge column: an illustration}

A two-span bridge having a span length of $20 \mathrm{~m}$ was selected to demonstrate the design of a column based on the expressions developed in this study. The bridge is supported by a $6 \mathrm{~m}$ high single column. The axial load on the column has been estimated as $3150 \mathrm{kN}$. The diameter of the column has been chosen as $1 \mathrm{~m}$. The material properties are: concrete strength, $f_{\mathrm{c}}^{\prime}=40 \mathrm{MPa}$ and yield strength of reinforcement, $f_{\mathrm{y}}=500 \mathrm{MPa}$. The bridge has to be designed for an earthquake shaking level of magnitude $7 \cdot 0$ and sitesource distanc of $50 \mathrm{~km}$.

The DB design of the bridge column can be carried out according to the substitute structure approach (Shibata and Sozen, 1976). The methodology is outlined below.

(a) Calculate the effective yield displacement $\left(\Delta_{\mathrm{y}}\right)$ based on the effective yield curvature developed in Equations 9(a)-9(d).

(b) Calculate the ductility demand based on the maximum allowable displacement $\left(\Delta_{\mathrm{u}}\right)$.

(c) Calculate the equivalent viscous damping ratio from the ductility demand at maximum allowable displacement (Kowalsky et al., 1995) based on a bi-linear force-displacement relationship using Equation 10

$$
\varsigma_{\mathrm{eq}}=0 \cdot 05+\frac{1}{\pi}\left(1-\frac{1}{\sqrt{\mu}}\right)
$$

(d) Calculate the effective stiffness $\left(K_{\text {eff }}\right)$ of the column using Equation 11

$$
K_{\mathrm{eff}} \approx \frac{4 \pi^{2} M_{\mathrm{eff}}}{T_{\mathrm{eff}}^{2}}
$$

where $M_{\text {eff }}$ is the effective mass and $T_{\text {eff }}$ is the effective period of the column. The effective period can be calculated from the displacement response spectrum for the equivalent viscous damping (Equation 10) at maximum allowable displacement $\left(\Delta_{\mathrm{u}}\right)$.

(e) Determine the base shear strength and the corresponding moment at the base for the design of column

$$
\begin{gathered}
V=K_{\mathrm{eff}} \Delta_{\mathrm{u}} \quad \text { and } \\
M=V H
\end{gathered}
$$

The effective yield curvature, $\phi_{\mathrm{y}}$, has been estimated to be $0.0054 \mathrm{~m}^{-1}$ (Equations (9a)-9(d)). The corresponding yield displacement for this cantilever bridge column subjected to applied lateral load induced by ground motion is estimated as

$$
\Delta_{\mathrm{y}}=\phi_{\mathrm{y}} \frac{L^{2}}{3}
$$

where $L$ is the length of the column. For a $6 \mathrm{~m}$ high column, the yield displacement is estimated as $0.0648 \mathrm{~m}$ by Equation 14. It is desired to limit the expected peak displacement to $2.5 \%$ of the height of the structure $\left(\Delta_{u}=0.025 \times 6=0.15 \mathrm{~m}\right)$ for the life safety performance level. The design ductility is therefore equal to $0 \cdot 15 / 0 \cdot 0648=2 \cdot 3$. The damping ratio for this level of ductility is approximately $16 \%$ by Equation 10.

A suite of response spectra for magnitude $=7.0$ and site-source distance $=50 \mathrm{~km}$ has been generated using the computer program GENQKE (Lam, 1999) considering hard rock site conditions. Figure 8 presents the average of six ensemble response spectra of the generated ground motions.

The effective period, $T_{\text {eff }}$, has been estimated as $2.0 \mathrm{~s}$ from the response spectrum (Figure 9) representing a damping ratio of $16 \%$. The effective stiffness has been calculated as $3170 \mathrm{kN} / \mathrm{m}$ (Equation 11). Hence, the required base shear strength, $\quad V=3170 \times 0.15=$ $476 \mathrm{kN}$ (Equation 12) and the corresponding moment

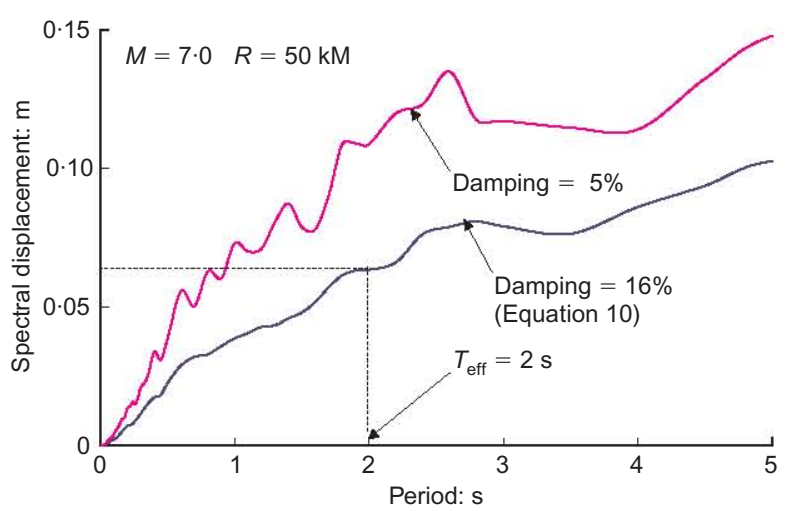

Figure 9. Average of six ensemble response spectra of generated ground motions using computer program (Lam, 1999) 
at the base of the column $=476 \times 6=2856 \mathrm{kNm}$ (Equation 13). Longitudinal reinforcement, $\rho$, of $1 \cdot 1 \%$ would be sufficient for this column.

\section{Conclusions}

Simple expressions for estimating effective yield curvature for normal- and high-strength circular RC columns have been developed based on momentcurvature analyses of more than 200 column sections. Such expressions can be easily programmed into an Excel spreadsheet and can be very useful for preliminary design of concrete columns and also for performance evaluation of existing columns.

Previous studies on effective yield curvature have been critically reviewed and the limitations of the studies in incorporating the influences of axial load, strength of concrete and amount of longitudinal reinforcement have been identified. The present study is a significant improvement over the previous studies as all the parameters that influence the estimate of yield curvature have been quantified.

The yield curvature is influenced by the size (diameter) of the section, the axial load ratio, the strength of concrete and, to some extent, the amount of longitudinal reinforcement and the thickness of the concrete cover. It has been observed that the accurate estimate of the effective yield curvature can be obtained when it is expressed in terms of the diameter of the gross section rather than the effective depth, as the concrete cover has insignificant influence.

The amount of longitudinal reinforcement does not have a significant influence on the effective yield curvature. Hence, the effective yield curvature can be estimated reasonably without explicitly considering the influence of the amount of longitudinal reinforcement. This is especially useful for preliminary design of concrete columns. However, the effect of longitudinal reinforcement may be important for the accurate performance evaluation of existing columns.

A DB procedure for the design of a bridge column has been presented based on the substitute structure approach using the developed expressions for estimating effective yield curvature.

\section{References}

Gomes A and Appleton J (1997) Nonlinear cyclic stress-strain relationship of reinforcing bars including buckling. Engineering Structures 19(10): 822-826.

Kowalsky MJ, Priestley MJN and Macrae GA (1995) Displacementbased design of RC bridge columns in seismic regions. Earthquake Engineering and Structural Dynamics 24(12): 1623-1643.

Lam NTK (1999) Program GENQKE user guide: program for generating synthetic earthquake accelerograms based on stochastic simulations of seismological models. Department of Civil and Environmental Engineering, The University of Melbourne, Australia.

Légeron F and Paultre P (2003) Uniaxial confinement model for normal- and high-strength concrete columns. Journal of Structural Engineering 129(2): 241-252.

Lehman D, Moehle J, Mahin S, Calderone A and Henry L (2004) Experimental evaluation of the seismic performance of reinforced concrete bridge columns. Journal of Structural Engineering 130(6): 869-879.

Miranda E and Garcia JR (2002) Evaluation of approximate methods to estimate maximum inelastic displacement demand. Earthquake Engineering and Structural Dynamics 31(3): 539-560.

Montes EH and Aschleim M (2003) Estimates of yield curvature for the design of reinforced concrete columns. Magazine of Concrete Research 55(4): 373-383.

Park R (1997) A static force-based procedure for the seismic assessment of existing reinforced concrete moment resisting frames. Bulletin of New Zealand Society for Earthquake Engineering 30(3): 213-226.

Park R and Paulay T (1975) Reinforced Concrete Structures. Wiley, New York, USA.

Paulay T and Priestley MJN (1992) Seismic Design of Reinforced Concrete and Masonry Buildings. Wiley Interscience, New York, USA.

Paultre P (2001) MNPHI: A Program for Sectional Analysis of Structural Concrete-user Manual. Department of Civil Engineering, University of Sherbrooke, Sherbrooke, Canada, CRGP Report No. 2001-01.

Priestley MJN, Calvi MC and Kowalsky MJ (2007) Displacementbased Seismic Design of Structures. IUSS Press, Pavia, USA.

Priestley MJN, Ranzo J, Benzoni G and Kowalsky MJ (1996) Yield displacement of circular bridge columns. Proceedings of the 4th Caltrans Research Workshop, California Department of Transportation, Sacramento.

Shibata A and Sozen M (1976) Substitute structure method for seismic design in R/C. Journal of Structural Division, ASCE 102(1): 1-18.

Discussion contributions on this paper should reach the editor by 1 April 2011 